\title{
Triangulate the Culture, Economy, and Social Capital (Interdisciplinary Approach)
}

\author{
Khademalizadeh Amir, Rezayee Jahdkon Mehdi \\ Allameh Tabataba'i University, Tehran, Iran
}

\begin{abstract}
Following the knowledge revolution, the role of knowledge in economic value creation became much more pronounced. Islamic teachings put emphasis on knowledge-based economy functions. The aim of this study is explanation of being consistent with the science coordination. This study was descriptive-analytic method. The results show that the Islamic teachings emphasize the progress and prosperity of the earth and provide capacity (power) authority, knowledge-based, inclusive approach to the dissemination of knowledge for the benefit of humanity. The important indicators of social capital, trust, collectivity, and cooperation, are affected by belief, opinions, values, and cultural norms and affection depth and strength of them. Progress of the development needs to pay attention to importance of culture and that's role in creation of base of interactions of society. Innovation in this research is explanation of being consistent with the knowledge-based Islamic economics that Islamic economics literature has not seen so far.
\end{abstract}

Keywords: social capital, culture, economics, development

\section{Introduction}

Determination, communication, and culture, and the economy influence each other on question of economic theorists and policy makers who are essential. The answer to this question requires definition of the culture and economy as well as the determination of the ultimate goal of planning and economic policy. The quality of comprehensive and sustainable development with the ultimate goal of socio-economic planning and policy-making is sent and given the cultural and spiritual needs with material needs of human societies from the most important criteria to assess economic theory and development programs considered. Social capital, though after two other capital - economic and human capital, have been raised, but in recent years there has been growing concern and day by day, not only in development but also in the discovery investors improve production efficiency and protect investments other to put more emphasis on its role and economic importance and unique role in the development of social capital on the one hand and the relation between the indicators of social capital, which consist of trust and cooperation, the foundation of the culture that the beliefs, values as well as their impute on the communities against the development or lack of social in traction and communications between members and the expression of society's culture the need to examine the relationship between social capital and culture reveals wisely. It's important for our society on the other hand to transit from "developing"

Khademalizadeh Amir, assistant professor in Economics, Allameh Tabataba'i University, Tehran, Iran.

Rezayee Jahdkon Mehdi, Ph.D. student in Economics, Allameh Tabataba'i University, Tehran, Iran.

Correspondence concerning this article should be addressed to Rezayee Jahdkon Mehdi, Department of Islamic Economy, Economy Faculty, Allameh Tabataba'i University, Ahmad Ghasir Street, Tehran, Iran. 
to "developed" and the ruling system of values and cultural back ground and heralding the claims call for more attention to the spiritual and cultural significance which will be added. Given the above, the paper will start with a presentation of the research literature. Conceptual framework is represented in second section. Then in third section, the theoretical foundations of the study will be reviewed and the relationship between social capital and culture will be analyzed. Discussion is presented in fourth part and finally fifth section concludes.

\section{Research Literature}

Examining the relationship between economy and culture as well as social and cultural capital requires transparency in the concept of social capital and culture. Different definitions and approaches that were discussed in relation to the economy and culture of as special relationship between the two issues are plotted. In this regard, the history of the concept of social capital is the first step and compares different definitions of the concept of culture and takes the appropriate way to continue research. Social capital is an interdisciplinary concept in sociology, economics, psychology, and other social areas applications.

The origin of this concept is sociology. The modern notion of the concept was first used in 1916 by Lyda Judson Hanifan and although had long been used in sociology, but nearly three decades, the field of economics is also entered. And interestingly perhaps explosive expansion of social capital literature in the past decade, was made mainly by the economist (Renani, 2006a). This term in recent years has entered the field of social science and economy, and a new window will open in the analysis and the recourse for seeking social and economic issues. In this context, extensive studies conducted by scholars and scientists and science theorists such as Jacobs (1961), Coleman (1966), Loury (1977), Ben-Porath (1980), Wlliamson (1981), Becker (1983), and Fukoyama (1995) have different definitions of social capital. Weber's (1930) primers usually know the culture and economy. In his article "The Development of the Capitalist Economic System in North West Europe and North America to Ethical Principles" (in some subdirectories) connects Protestantism, but perhaps as to its substantial tradition in economic thinking, he has the ideas of Adam Smith, who is considered by many founders of economics. Smith (1795) says that moral emotions in mutual empathy are what keep society. Because people naturally tend to put themselves in the position of others, ruthlessly exploit each other, but use normal and moral behavior as thus, inhibition of self inherent in the people leads to a peaceful and progressive society.

\section{Research Question}

One main question in this research is that: what and how do social capital and economics make relationship with culture at its heart associated with the development of its culture?

\section{The Main Hypothesis}

In line with scientific answers to this question, the following hypotheses have been proposed:

- Original hypothesis: the existence of an adequental level of social interaction in the form of social capital facilitated economic trend and achieve the appropriate level of influence of culture on society.

- Second hypothesis: the effect of culture on social and economy on social capital is not unidirectional but the economic growth and development on the level of social capital as well as culture and indices are effective.

\section{Conceptual Framework}

The concept of social capital and culture despite the wide spread use of the common and scientific discourse requires careful consideration and to be clear enough to avoid a bad misunderstanding on the judgments and opinions. It is not possible to accept or reject without controversy. 
Social capital. Jacobs (1961) in the book The Death and Life of Great American Cities Social Capital Intensive Network knows where the old city of hat in maintaining clean lines of the lack of street crime and other decisions about improving the quality of life compared with formal institutions such as the police protection and law enforcement agents which have more authority to show. A concrete example of this definition in today's world can be found in the environmental Ngo's. The social network for Ngo's, and some powerful forces to create environment even in support of the government's development projects are halted. It is the same as Colman (1966), social capital involves a social framework that facilitates the relationships among individuals within this framework, so that the lack of it may achieve a certain goal into the community imposing more costs. Loury (1997) knows the sources of social capital in the natures of family relations and social organization and the use full for social development. The definition of social capital relationships between members of a family group of friends or partners of a company is defined as a relation (Ben-Porath, 1980), Williamson (1981) and Becker (1983) follow Ben Pratt's studies to investigate the ways in which the social organization of economic institutions established a series of economic studies that the new institutional economics is called. Fukuyama (1995) believes that social capital can be defined as a set of informal norms or values defined. Provided that there are norms of positive values such as honesty, what follow is the multiple definitions of social capital concept including concept such as trust, cooperation, and achieving a target group based on common values and standards of society to lead. So what can be concluded from this definition is that although social capital may be due to forces of attraction between members of a group, repulsive forces between different groups in society are necessarily appositive factor. But certainly to promote and facilitate the socio-economy performance of communities is an essential factor.

Culture. Ashuri (2014) despite category definitions of culture in titles, descriptions, history, norms, psychology, structure, and phenomenon, admited the precise application of the concept with its definition begins with Taylor. Taylor (1871) defines culture: culture integrity is intertwined knowledge, religion, art, law, morals, and any other capabilities and habits acquired by man as a member of society. Giddens (2009) introduces culture as society life style habits and customs along with the commodities they produce, and points out that the system refers to interacting with people who have a common culture to each of them. No culture can exist without society as there is no society without culture. He also emphasizes that culture consists of values that are members of certain group. Following norms and material goods they produce, culture of a given society lifestyle, habits, and customs, along with material goods they produce is called their customs and habits. Fulady (2008) pointed out that the culture of the society as a person of character emphasized that human personality is created through the interaction with others through this action, we'll learn how to build a harmonious society, and regulate our lives. Without being socialized, one can not think, think or think in society as something worthy or normal, he spoke and responded to others. The social life of man is culture-oriented. Parsina (2003) points that culture is of knowledge culture of knowledge of the common mentality of the world's population or environment. For the purpose of knowledge of mental awareness, perception, and assertion, the general senses are feeling, emotions, attitudes, belief, and habits and customs and also learning. Any type of awareness, whether as a simple thought or within character of people, is permeated and they will serve or be at odds with the collective or will actually be in the realm of culture. The result is that the research culture will be providing the kind of insight and understanding of attitude towards life, a man of the world... and norms of behavior and attitude often unconsciously based on the insight of a community determines the individual and social behavior. 
The history of the relationship between culture and social capital in Iran. The most comprehensive and most important work in relation to the concept of social capital and its relationship to culture in Iran, was written by Renani and Moayedfar (2012) as moral decay cycles and economy. In the book of account of social capital and economic and cultural characteristics of the concept or rationality, there are three categories: instrumental, normative, and emphasizing ritual, which emphasizes that social capital of a community is based on the rationality of the society. Nazarpur and Montazeri (2010) believe that application of the theory of social capital regardless of the dimensions and conditions of its implementation is incomplete. The revision of the concept and understanding of its component according to religious and minorities is essential for clarifying the role of social capital in economic development. Nazarpur and Montazeri (2008) emphasized that social capital is in clouds of the institutions, relationships, and values that govern the actions and reactions of the people and the realization of social and economic development impact but social capital is not the simple sum of the institutions of society which is rather like the mortar that binds his aforementioned institutions. Social capital also includes the values and common norms for social behavior in the behavior of individuals and their trust in each other and the common sense of civic responsibility are reflected. Therefore, although the views expressed partly implied considering the issue of the relationship between social capital and cultural rights is respected, but any-doctor Renani even - has not been considered. In other words, if what is at stake requires careful consideration of the relationship between culture and social capital, but in none of the content this important plan is clearly reviewed.

Its scientific background, culture and social capital abroad. Mariano Grondona (2000) distinguishes between intrinsic and instrumental value defining sustainable development as development that is based on intrinsic value. He acknowledges that the intrinsic value is that whose costs and benefits, which are approved, we paid no attention to. Values and instrumental values are beneficial to us because we are protected. And he stresses that the economic value usually does not have the means and the ability to create a sustainable development and the cultural values or "morality" are the basic for sustainable development and a measure of the value of the instrument, and there for its economic development as a cultural process.

De Jong (2009) in the book Culture and Economy says that any history of ideas is about the relationship between culture and the economy and at the same time based on the relationship between the two forms of economy states. He stressed that since the late nineteenth century at least, there are two types of economics. One of the formal economy that we all know and efficiency of the treat out is meant to save and other fundamental tradition in economics, which focuses on the study of economy, the study of society that ensures the production, use, and distribution of goods and services. He also expressed the view that the history of the competition against the official economy and institutionalize approach reached its peak and pointed out that there were still areas of the economy and culture still plays an important role. This new research field is economic development. Throsby (2011) presents two definitions of culture, the first of which has a nominal aspect, and the other is a descriptive one. The first definition of culture as a set of attitudes, beliefs, customs, traditions, values, and practices common in any group is known or is proposed. And the second definition describes culture as the activities that have three innovative features of delivering a symbolic and intellectual property is eligible. He admits that the economy cannot be separated from the culture in the first definition, although the formal precision of a modern economy and an emphasis on unbiased scientific method to test the hypotheses are possible. This concerns the economy as a discipline without cultural context raises. Sen (1998) emphasizes that: 
Dedicated development experts, keen on feeding the hungry and banishing economic poverty, are often impatient with what they take to be premature focusing on culture in a world of manifold material deprivation. How can you (so the argument runs) talk about culture - poetry or music or painting — while people succumb to starvation or undernutrition or easily preventable disease? The motivation behind this criticism cannot dismissed, but the artificially separatist-and stage - wise - view or progress is under and unsustainable. Even economics cannot work, as Adam smith noted, without understanding the role of, "moral sentiments", and Bertold Brecht's note of cynicism in his threeponny opera, food comes first then moral's, is more a statement of despair then of an advocated priority.

Tittenbrun (2013) believes that the concept of trust which is usually considered as the core of social capital is more based on perceived cultural interpretation something that makes social economic reality hidden. The ideological interpretation of social capital knows. Six, Van Zimmeren, Popa, and Frison (2015) believe that concept of social capital can be followed by an analysis of the broader concept of trust. For them, the concept of trust-based social structure is often used as a feature explaining collective action. Although the concept of social capital is implicit in the theory of neo-liberal values constituting only society which will emerge, special attentions of special attentions are attracted to the relevance of culture and social capital in relation to both these issues with the concept of trust. Aside from the point that somehow Brown Titan's against the cultural and ideological approach to the issue of trust and social capital, other experts have stressed the importance of the connection.

\section{Theoretical Foundation Research}

Definition economy cannot and should not be considered apart from its purpose. Undoubtedly, resource allocation should be based on the goal of social well-being of all members of society. Prosperity and social well-being can also provid without the sense of the rule of justice. Accept this regardless of the momentary interests of the individual and collective interests disruptive in a way that makes it accessible. The adoption of this practice and preparation for constructive interaction facilitate this process by society and only in a certain kind of thinking and insight that will be possible to provide areas of the interactions. This is why the culture, attitudes, and norms, based on an effective role in realizing this vision and engaging in other words social capital, which in turn provides benefits to society of prosperity and justice provides.

\section{Social Capital, Through Happiness and Justice}

The main objectives of the plan governors, social planners, and social welfare are that this issue is also subject to the establishment of justice. Interestingly, the goal of economics is the same, the purpose of economics is to say. This is important the optimal allocation of resources means that the person of their trade and try and in other words, your life satisfaction and happiness is the core of this feeling and situation constitutes justice (Renani, 2007). Economic correspondence to the two categories of interest has given to each criterion. Mercantilism or merchants, wealth and prosperity of the country's capital and physiocrats saw more fitness with nature. The more classical and neoclassical terms and you are no longer the standard universal "nature of release knows how to grow" with the "laissez-faire" and "invisible hand" followed. In modern times, new technology and training human resources knowledgeable and efficient measures that lead to prosperity and communities were communities and considered. But studies ultimately led to this development as the ultimate criterion of intellectual development and personal well-being of a society with a particular behavioral habit and scientific and technical ability is special, developing the ability to use advanced and expensive goods and services, but also the ability of human beings to be able to produce these goods. So even the ability to produce 
these goods is not enough, but it should be possible that humans produce advanced products, not only production but also to improve their new or enhanced products to improve their communication. In other words, happiness is more important than economic capital and human capital, social capital is subject to the possibility of production and the correct use of the founds provided and the process to sustain. Social capital is the trust, solidarity, cooperation, and the rule of law and hence social capital "necessary" and the primary means of "happiness" in the new communities. As the second issue of justice is another condition for achieving economic prosperity on the one hand and accurate performance is required. Happiness, in other words is the same "moral action and in accordance with the law" on the other hand justice enumerated and also to put "principles" as defined in. Obviously, the origin of law and respect for ethics and the principles of justice can be controversial and on what way and on what the source of these rules is available on the debate and differing opinion is accessed but that happiness is to act in accordance with the principles of morality and law and justice specific criteria that can be agreed upon by all views. If social capital rules and principles of the mass of the people as a community we can confidently say that social capital is the founder of welfare and social justice can be considered a prerequisite for the realization of these things.

\section{What Is Social Capital?}

All studies of social capital and its relationship with economic development are considered one of the serious issues in the economy. Here it may be asked why a social concept as "capital" is used. The simple answer is usually for things that are a "growth engine" of the economy considered to be used as capital. Meanwhile, the capital of "accumulation" of good thing (goods, money, and other values) also evokes in any cumulative, meaning "gradually" also lies, when we say that "social capital" is good thing that is gradually accumulative and can act as an engine of the economy (Renani, 2006a). We know that we are dealing in other investment, financial, or economic capital and human capital. Almost since the collapse of the east bloc and the beginning of the 1990s, the economists found that some communities or countries are moving rapidly towards the development sphere while not physical capital and human capital are economically appropriate and not very widespread and have been accumulated. Here was found in another capital in the name of "social capital". So economists focused on social capital and its value gradually rose until it saw economic growth engine. They concluded that if the spread and accumulation of social capital in a society is enough, human capital and economic capital, other areas are flooded to the community. They found that, in fact, the main factor to attract human and economic capital to each region is sufficient accumulation of social capital. The good empirical evidence is collected in the field. Apart from developed countries, in developing countries the evidence of leading was obtained. Even the development of the different regions was studied in developed countries because differences in social capital in different regions of the country were detected. For example, Putnam's study (1993) showed that the level of development of northern and southern Italy is due to the wide spread activities of the mafia in southern Italy, the level of social capital is much lower than the north of the country. But what is social capital? In sociology, in any social relationship that we have established, "the nodes or social links" say (Renani, 2006b). Nodes with the formations of a "social supply" begin. Society saved the same social attitudes and simple communication. Remember when they continue to be repeated in other cases gradually they become asocial link or node. That relationship becomes institutionalized and stable. With every save of social communication and collaboration between them, gradually more and more people trust and rely on each other increasingly. This relationship is the trust and social capital that exists among a gathering of 
the community can make social interactions more done with ease and fluency. The amount of capital with their continuity and success (it means, when the behavior of each side, the other side is expected) is getting more and more. Social capital has three levels. The first level is the micro-level or individual level. The relationship between two people is like they together have an intimate relationship and cooperation and trust are of this type. This is called procedural rationality social capital. Now, if a set of people interact with each other and have across, so that a social network (egg, a grope, a party, a local community, etc) and members of the network can rely on, second-level or mid-level social capital is that called procedural rationality again, if these groups and individual networks at the level of the whole community together are to communicate, to work together to tell the expressive rationality (Renani \& Moayedfar, 2012). In sociology mainly three indicators are used to measure social capital. The first one is trust, which has two levels, personal confidence and public trust or extended. Personal trust is to a family member or colleague or anyone else who is trusted by him. Public confidence is the specific recognition to those who do not trust them. The general confidence index and now it came to be important in terms of economics and sociology (Renani, 2007). The second indicator is social participation. Partner must have three characteristics, leading to social participation. First, it is rational, not emotional meaning. Second, it should be continuous and third, be consistent and that is organized. And the third is to help index. Cooperation means that you have no expectation and obligation to those who do not know him and he is not expected to compensate for help or serve. It is important to note that in addition to these three indicators of the economy, other factors are considered. In other words despite the three main benchmark indexes for economists, the behavior of individuals within the frame work of formal or informal arrangements is also a measure of social capital. Formal and informal arrangements such as rules, religious, and moral values of our behaviors towards others are predictable and controllable. The predictability of behavior, the formation of self-help to be more precise predictability for economists index provides general confidence index.

\section{Discussion}

Economy as simple and clear review of allocation of scarce resources to unlimited needs has to be defined (Dad-gar \& Rahmani, 2012). In this regard, the most important allocation mechanism, and the most important market forces of supply and demand will be introduced. In other words, the engine of the economy of the exchange, means that people have to learn their needs and obtain the required resources which are required to exchange and this exchange is done better in the market and this transaction is the supply and demand factors in different sources and requires the parties. But all these systems are based on a more important principle of rationality or rational choices in the market, based on knowledge of the needs, priorities and values, humans entered each exchange. In this regard, two issues are important, first and second sense of rationality and rational behavior favorable to exchange and cost paid for this transaction. However high the level of the wisdom is, low the transaction costs are, and high the market efficiency of economic system, the economics that is optimal allocation of resources among segments of society will be achieved. Three levels can be considered as rationality (Renani \& Moayedfar, 2012): rationality, normative, spiritual. It is a socio-historical rationality and reason within the meaning of the terms and limitations of real life. In this case, instrumental rationality is compatible with the target device. In other words, a level of instrumental rationality is rationality in daily life to compare and choose between objects and actions to be taken to achieve the target or desired value, the best means and methods to be selected. Normative rationality is the adaption of behavior according to social 
desirability. The adaption of tools and methods to achieve individual goals picks with rituals and values are accepted by society. Compliance tools and ways that people choose to live with their human dignity forms third level of spiritual wisdom or rationality. Instrumental rationality of the goal and the action determines the quantity and the "quantity of work" dealing with the normative rationality "quality work" and spiritual wisdom with "nature of the act" are linked, among the rationality of formal and informal arrangements associated with normative rationality and moral rationality. In other words, social capital formation begins with freedom of choice and instrumental rationality and instrumental rationality to the rationality of religious conversion, and thereby also expands until it becomes saturated social capital. Society is rich in social capital, the degree of adaption to environmental conditions and increaseing spiritual wisdom and to be clear to people helps more on spiritual wisdom of their functions the social capital of a society by the first type of rationality and changes in rationality, in turn, according to the criteria for the selection of economic performance which makes them change. Therefore, with the promotion of social capital and levels of growth and rationality in a society of mutual respect and the attention to improving the reliability and predictability of behavior in society more in the light of high social capital, transaction costs can be further reduced. And reducing transaction costs to their contribution to a more efficient market and greater economic growth and social development in a proper social order and rationality, will improve the level of social capital. Social capital is based on social communication and interaction of community. But the communication and social interaction, social capital are not indicated. Factors of interpersonal communication among members of a society have certain features, and this gives them the ability to facilitate the economic and political process and factors are indeed, social capital is trust, participation is voluntary and cooperative. Among the factors referred to a more prominent position of trust, Fukuyama (1995, p. 27) says about it:

The ability to associate depends, in turn, on the degree to which communities share norms and values and are able to subordinate individual interests to those of larger groups. Out of such shared values comes trust, and trust, as we will see, has a large and measurable economic value.

Fukuyama sees not only the issue of trust in social capital but social capital focusing on the role of values and norms in the realization. The indicators of social capita, trust, partnership can be a good bridge between social capital and culture and consequently provide between culture and economy. We are naive if we think that these behaviors between members of a society can be achieved only by repeated exchanges. Selective and autonomous beings are based on their vision, experience, judgment, and choice. Without doubt, feedback options prior to selecting the next influence thinking but also play an important role in this case. That is why, despite the apparent similarities and relatively uniform human experience, we face with deep cultural differences globally. Collective behavior and social interactions between the climate and the environment in addition to community are based on vision of the world and people it is governing. This attitude and insight, in turn, due to the superiority of certain types of behavior, norms, and interactions are influencing on the other. Therefore, according to the definition of culture, the knowledge and the norms prevail in a society where the dominant culture is a determining factor in community action and social activities of the community. Another important point that should be mentioned is the role of education in creating social capital of the importance of intergenerational relationships to form and sustain social capital. According to the humane society and constantly changing and evolving generations, this, without the transfer of knowledge, concepts, beliefs, attitudes, and norms, can break the links? Which is considered the opposite of continuity and bond strength? 
One of the main factors of social capital in a community is a strong and enduring relationship between different generations of the community. Communication accumulation of different generations in a community of the most effective forms of relations among people is authentic and reliable. So the culture of intergenerational learning through effective agent of social capital is affected. But the influence of culture on social and economic capital is also an important issue that should not be neglected. The economic infrastructure and economic interactions in a society are shaped by expanding public education to better meet the needs of minority community cultural interaction provided. The controversy to meet economic needs in a less developed society happens and has always been a precursor to avoid the possibility of the participation of people thus trust and cooperation will degrade. Of course, no doubt that the impact of the economic factors linked to needless culture and cultural content is desired. Whatever the logic of the vision forming a culture of greater strength and resistance allows its owners to be more devastating and vice versa with the basics of cultural insecurity, population changes and shocks than it was less resistance power and in spite of these issues which will be further endangered. Therefore, the rate of convictions is in relation to the wise and knowledgeable knowing creator of the universe and the Day of Judgment and rewards to create the character of honesty, trustworthiness among believers and therefore the impact of the adaption of behavioral traits contributes to empathic and sympathetic members of the community and the interests of personal interests and cooperative approach in choosing all responsive to cultural differences in the level of social capital in different communities and to justify the difference in levels of development. However, it is also noteworthy that the public experiences from the past behavior of the rulers and the social interactions and the quality of infrastructure and the amount and distribution of previous resources can change the effect of this belief.

\section{Summary and Conclusions}

Taking together presentation about social capital, with emphasis on the three indicators that were the talk of trust, partnership, and cooperation and given the important role of culture in the achievement of all three of these indicators, it can be said that:

1. Culture of solidarity and community is based on vision on the one hand and on the other hand has, the incidence and effects of different sectors including life need from the community, political, economic and...

2. The core of culture is the vision of society that religion, philosophy, science, and support are affected. These are summarized in the worldview of the crystallization of a society.

3. Human beings are autonomous and options are based on your choices and rationality, which is the preferred utility, and is the optimal choice according to the conditions. The norms of behavior and the circumstances he based on his vision for his understanding and interpretation are allowed to do.

4. Relations of a society are not separate from action and human behavior based on his rational choices. The different roles of a society are in different areas of public life such as politics, the economy is doing well because it is based on the vision of the community being affected by the dominant ideology and a manifestation of the culture of society.

5. In consideration of any social action and their existence, promoting social capital of society was affected by its nature, it is also considering the possibility of promoting cultural identity and the feasibility assessment will be desired. As a result, the main hypothesis is that the appropriate level of social interaction is influenced by the culture established. 
5. Social relationship also influences the attitudes and insights about the impact of the sub assume therefore accepting the culture of social interaction, including economic cooperation and the cultural influence of the economy is believable.

\section{Future Offers}

Our country is in transition from stage to stage of development and is developing like other countries that are faced with many problems crucial to this transition. Given the cultural nature of the Islamic republic, claims for justice and anti-oppression have always been seen as a threat by the big powers and targeted by military attacks, political, economic, and cultural. Therefore, the officials of the sacred system in their statements always have emphasized the importance of preparedness increasing in all areas. In this respect, in recent years it has been emphasized more than others resistance of culture and economy is also an important issue. It does not cover these two issues and overlaps of the experts acknowledge that is basis of the realization of economic strength rather than economic infrastructure, culture, and spirit of resistance. Therefore, investigating the role of culture in achieving social cohesion and social capital is directed toward the development of balanced and endogenous and economic relations seeking to destroy the evil tricks can be fertile ground for the development objectives of the economic program providing the resistance.

\section{References}

Ashuri, D. (2014). Defends and concept of culture. Tehran, Agah.

Becker, C. S. (1983). A theory of competition among pressure groups for political influence. The Quarterly Journal of Economics, 98(3), 371-400.

Ben-Porath, Y. (1980). F-connection: Families, friends, and firms and organization of exchange. Population Devel. Rev., 6(1), $1-30$.

Coleman, J. S. (1966). Equality of education opportunity study. Washington, DC: US Department of Health, Education, and Welfare, Office of Education. National Center for Education Statistics.

Dad-gar, Y., \& Rahmani, T. (2012). The fundamentals and principles of economics. Gom, Bustan-e Ketab.

De Jong, E. (2009). Culture and economics: On values, economics and international business. London: Rutledge.

Fukuama, F. (1995). Thrust:Tthe social virtues and the creation of prosperity. New York: Free Press.

Fuladi, M. (2008). Culture and cultural engineering. Technology of Culture, (1), 183-220.

Giddens, A. (2009). Sociology (6th ed., revised and updated with Philip W. Sutton). Polity Press.

Grondona, M. (2000). A cultural typology of economic development. In L. E. Harrison and S. P. Huntington (Eds.). Culture matters-How value shapes human progress (pp. 44-55). New York, USA: Basic Books.

Jacobs, J. (1961). The death and life of great American cities. New York: Random House.

Loury, G. (1977). A dynamic theory of racial income different in women. Minorities and Embayment Discrimination, 153-188. Edited by P. Wallace and A. La-Mond. Lexington, Mas: Lexington Books.

Nazarpur, M. T., \& Montazeri, M. (2008). The confidence culture in religion thought and its role in economic development. Islamic Economics, 7(31), 37-68.

Nazarpur, M. T., \& Montazeri, M. (2010). Social capital and economic development: The study about social cooperation from Islamic perspective. Islamic Economics, 10(37), 57-88.

Parsania, H. (2008). Relationship between science and culture. Strategy for Culture, 1(2), 51-64.

Putnam, R. D. (1993). The prosperous community: Social capital and public life. The American Prospect, 4(13), 27-40.

Renani, M. (2006a). The role of social capital in economic development. Dariche Quarterly, 3(10), 4-23.

Renani, M. (2006b). The increase of social capital and loose the economic politicize in Iran. Ayin Monthly, (6), 6-12.

Renani, M. (2007). Comeback to Socrates: Social capital the tools of produce happiness. Dariche Quarterly, 4(14), 7-23.

Renani, M., \& Moayedfar, R. (2012). The decline cycles of morals and economy. Tehran, Tarh-e No.

Salehnia, N., \& Her, C. (2010). The role of culture in economic development. Cultural Engineering, 43(44), 66-79.

Sen., A, (1998). Culture freedom and independence. UNESCO World Culture Report, 317-321. 
Six, B., Van Zimmeren, E., Popa, F., \& Frison, C. (2015). Trust and social capital in the design and evolution of institutions for collective action. International Journal of the Commons, 9(I), 151-176.

Smith, A. (1957). The theory of moral sentiments. Minneapolis, MN: Filiqarian Publishing.

Taylor, E. B. (1871). Primitive culture (Vol. 1). London: John Murray.

Tittenbrun, J. (2013). Social capital, trust and ideology. European Journal of Interdisciplinary Studies, 5(1), 8-25.

Throsby, D. (2001). Economics and culture. London: Cambridge University Press.

Weber, M. (1930). Protestant ethic and sprit of capitalism. (P. Tarlott Trans.). London and New York: Rutledge.

Williamson, O. E. (1981). The economics of organization: The transaction cost approach. The American Journal of Sociology, $87(3), 548-577$. 